\title{
Sensitivity of Pipistrellus Nathusii Kidney Diploid Cell Strain to Viruses of Rhabdoviridae, Reoviridae, Bunyaviridae and Paramixoviridae Families
}

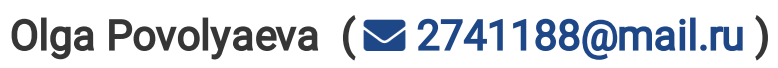

Federal Research Center for Virology and Microbiology

Anna Chadaeva

Federal Research Center for Virology and Microbiology

Irina Sindryakova

Federal Research Center for Virology and Microbiology

Oksana Lapteva

Federal Research Center for Virology and Microbiology

\section{Sergey Yurkov}

Federal Research Center for Virology and Microbiology

\section{Research Article}

Keywords: bats, diploid cell strain, virus, quarantine diseases.

Posted Date: August 20th, 2021

DOI: https://doi.org/10.21203/rs.3.rs-820565/v1

License: (c) (i) This work is licensed under a Creative Commons Attribution 4.0 International License. Read Full License 


\section{Abstract}

The discovery of a significant number of viral pathogens in bat tissue samples and excrement point to a potential prominent role of chiropters in the maintenance and spread of human and animal diseases. It also indicates the potential sensitivity of bat cells to a broad spectrum of viruses. The migratory pipistrelle bat, Pipistrellus nathusii, inhabits northeastern Europe and typically migrates to the southwest. Our study revealed the sensitivity (susceptibility) of a diploid cell line, derived from the kidney of $P$. nathusii to several transmissible animal disease causative agents such as Epizootic hemorrhagic disease, Akabane disease, Vesicular stomatitis virus and Peste des petit ruminants. High sensitivity of the $P$. nathusii kidney diploid cell line to viruses from various taxonomic groups allows them to be recommend for extensive use in virological studies.

\section{Introduction}

Currently, members of the order Chiroptera are considered to be one of the most important reservoirs and carriers of causative agents of particularly dangerous human and animal diseases. [1-3]. Genomes of viruses from different taxonomic groups have been detected in tissue and excrement samples taken sampled from bats [4]. Identification of these pathogens in bats has been carried out mainly using molecular genetics. Studying the biological properties of virus isolates which transmit from Chiropterans to target animal species is hampered by the absence of vivaria for bats, as well as the particular immune response of this mammalian species [5]. Furthermore, the most frequently used ("traditional") cell cultures are not effective enough for the isolation of viruses persisting in bats.

Therefore, obtaining cell cultures from tissues and organs of different subspecies of bats is relevant and solves problems regarding primary isolation and subsequent investigation into the biological properties of viruses. Additionally, it helps the assessment of the possible role of tissue-donor bats in the formation of natural foci of infection.

Studies on the susceptibility of bat cells have only been carried out on a few viral pathogens; most relating to causative agents of human disease. I. Eckerle et al. immortalized trachea cells lines from Carollia perspicillata (Seba's short-tailed bat) and Eidolon helvum (Straw-colored fruit bat) of the suborders Yangochiroptera and Yinpterochiroptera, respectively. These cell lines were characterized by susceptibility to viral infection with Rift-Valley fever virus and Vesicular stomatitis virus (Indiana strain) [6]. G. Vrameri et al. obtained cell lines from twenty different organs of Black flying foxes (Pteropus alecto) which were sensitive to Hendra and Nipah viruses [7]. A new bat cell line (NIV-BtEPC), taken/harvested from the embryo of a Plocamopherus ceylonicus, developed by D.T. Mourya and colleagues was susceptible to Chandipura (CHPV) and novel adenovirus (BtAdv-RLM) [8].

Earlier, our group developed a stable epithelial cell line from the kidneys of $P$. nathusii (PKDCL) [9]. In another study, this diploid cell line demonstrated the ability to maintain reproductions of Bluetongue virus, Rift Valley fever, Lumpy skin disease virus and Myxoma virus [10]. 
This study aimed at further exploring the range of susceptibility of diploid cell lines, derived from bat tissues to viruses from different taxonomic groups. Including those posing a risk of being introduced to, and spreading in, European countries.

\section{Results And Discussion}

Morphologically, PKDCL is characterized by epithelial-like polygonal cells containing oviform or ellipsoidal karyons with 1-3 (sometimes more) rounded nucleoli varying in size. The nuclear matrix was uniform (Fig. 1).

Virological tests carried out between passages 14-43 showed commonality between, and active proliferation of, the cells in the culture.

In this period, with the replanting coefficient 1:2-1:3, the confluent monolayer developed within 48 hours and persisted without changing the medium for 45 days (the period of observation).

Earlier, we demonstrated the sensitivity (permissivity) of this diploid cell strain to bluetongue virus, lumpy skin disease virus and myxoma virus [10]. In this study, we assessed its sensitivity to RNA-viruses belonging to different families: Rhabdoviridae, Bunyaviridae, Reoviridae and Paramixoviridae. For this study, viruses causing transmissible animal infections were selected, including the Peste des petits ruminants virus, which is currently posing a risk of being introduced to, and spreading in Russia.

The reproduction of VSV, with a multiplicity of infection (MOI) of $0.1-0.01 \mathrm{TCD}_{50} /$ cell in PKDCL, revealed early signs of CPE in the form of slight rounding of cells on the second day post-inoculation. On the third day, the delamination of infected cells from the substrate, followed by lysis and destruction of the monolayer, was observed in the cell culture. The accumulation of the virus in PKDCL reached 7,5 $\pm 0,25 \mathrm{lg}$ $\mathrm{TCID}_{50} / \mathrm{CM}^{3}$. In the control cell culture (L-929), this parameter was $6,75 \pm 0,25 \mathrm{Ig} \mathrm{TCID}_{50} / \mathrm{cm}^{3}$.

Akabane virus (MOI 0,1-0,01 TCD 50 /cell) did not cause CPE. Its titer did not exceed 3,5 $\pm 0,25 \mathrm{lg}$ $\mathrm{TCID}_{50} / \mathrm{cm}^{3}$, corresponding to the amount of initially introduced virus. While the accumulation of AKV in the control cell culture (CV-1) was up to $6.75 \pm 0.25 \mathrm{lg} \mathrm{TCD} 50 / \mathrm{cm}^{3}$.

EHDV with $\mathrm{MOI}$ of $0,1-0,01 \mathrm{TCD}_{50} /$ cell, caused slight CPE on the second day post-infection which was expressed by a partial lysis of the monolayer. Cell destruction was noted, in addition to elongated cells along the substrate forming strands. Infectious activity of EHDV in P. natussii kidney cell culture was 5,0 $\pm 0,25 \mathrm{lg}$ ТЦД ${ }_{50} / \mathrm{cm}^{3}$. In the control culture CV-1, its activity was $6,25 \pm 0,25 \mathrm{lg}$ ТЦД

Migratory routes of bats cover territories of Russia with a high density of small ruminants. Furthermore, causative agents of disease affecting animals belonging to the subfamily Caprine, including PPRV, may 
potentially be circulating in these territories, as well. Consequently, we assessed the sensitivity of PKDCL to this virus.

It was found that in PKDCL, the PPR virus with a MOI rate of $0,1-0,01 T C D_{50}$ /cell caused rounding and detachment of infected cells from the substrate accompanying with lysis and destruction of the monolayer on the fourth day post virus introduction. The virus accumulated in PKDCL cells and reached levels of $7.75 \pm 0.25 \mathrm{Ig} \mathrm{TCID}{ }_{50} / \mathrm{CM}^{3}$. That is much higher than in the control infected sensitive cell culture - GT $\left(4,25 \pm 0,25 \mathrm{lg} \mathrm{TCID}_{50} / \mathrm{cm}^{3}\right)$.

In parallel, to compare the dynamics of CEP development, we used cultures sensitive to each virus (CV-1, L-929 or GT). The summarized results of virological studies are presented in Table 1.

Table 1

Sensitivity (susceptibility) of the diploid cell line P. nathusii kidney to viruses $n=3$

\begin{tabular}{|c|c|c|c|c|c|}
\hline \multirow[t]{2}{*}{ № } & \multirow[t]{2}{*}{$\begin{array}{l}\text { Virus, Family, type } \\
\text { of genome }\end{array}$} & \multicolumn{2}{|c|}{ Diploid cell line $P$. nathusii kidney } & \multicolumn{2}{|c|}{$\begin{array}{l}\text { Sensitive (control) cell } \\
\text { culture }\end{array}$} \\
\hline & & $\begin{array}{l}\text { Time of CPE } \\
\text { observation of (dpi) }\end{array}$ & $\begin{array}{l}\text { infectious activity } \\
\mathrm{TCID}_{50} / \mathrm{ml}\end{array}$ & $\begin{array}{l}\text { Cell } \\
\text { Line }\end{array}$ & $\begin{array}{l}\text { Infectious activity } \\
\mathrm{TCID}_{50} / \mathrm{ml}\end{array}$ \\
\hline 1 & $\begin{array}{l}\text { VSV, } \\
\text { Rhabdoviridae, } \\
\text { RNA }\end{array}$ & 3 & $7,5 \pm 0,25$ & $\begin{array}{l}\mathrm{L}- \\
929\end{array}$ & $6,75 \pm 0,25$ \\
\hline 2 & $\begin{array}{l}\text { AKAV, } \\
\text { Bunyaviridae, RNA }\end{array}$ & $\mathrm{H} / \mathrm{O}$ & $3,5 \pm 0,25$ & CV-1 & $6,75 \pm 0,25$ \\
\hline 3 & $\begin{array}{l}\text { EHDV, Reoviridae, } \\
\text { RNA }\end{array}$ & 3 & $5,0 \pm 0,25$ & CV-1 & $6,25 \pm 0,25$ \\
\hline 4 & $\begin{array}{l}\text { PPRV, } \\
\text { Paramixoviridae, } \\
\text { RNA }\end{array}$ & 4 & $7,75 \pm 0,25$ & GT & $4,25 \pm 0,25$ \\
\hline No & * not detected & & & & \\
\hline
\end{tabular}

In the experiments testing the susceptibility of DCLPK cells to the viruses, the control (uninfected) DCLPK remained its typical morphology, and no CPE was observed.

The characteristics of CPE caused by the viruses in DCLPK cells is presented in Fig. 2.

Analysis of the results of the virological studies has shown that the subcultures of these cells are sensitive to VSV, EHDV and PPRV, and can be considered as a promising cell substrate for primary isolation and further study of these viral pathogens.

With respect to the high infectious activities of VSV and PPRV in DCLPK, exceeding their activities in the control sensitive cell cultures, we carried out a control of their authenticity using molecular methods. 
For this purpose, amplicons of VS and PPR viruses were produced, and nucleotide sequencing was carried out to determine which branch they belong to. Obtained sequences were compared with sequences from the GenBank database by using "Blast" software (https://blast.ncbi.nlm.nih.gov/Blast.cgi). It was confirmed that the obtained culture substrates contain VSV and PPRV.

Additionally, the authenticity of CPE caused by PPRV was confirmed by two serological methods: neutralization test (NT) and ELISA. To perform the NT we used 2-day cell monolayer on the 40th passage grown in 96-wells templates.

The reaction was evaluated based on the dynamics/manifestation of $\mathrm{CPE}$, and by comparing the values of the Reed-Muench virus titrations between normal and specific sera. The calculations revealed a neutralization index $(\mathrm{NI})$ of $10^{3,25}$ or $3,25 \mathrm{lg}$.

Antibodies against PPRV were detected in serum samples from sheep immunized by PPRV and infected cultural material (see material and methods).

Thus, the results of NT and ELISA tests confirm the authenticity of the PPR virus cultivated in the diploid $P$. nathusii kidney cell line.

\section{Conclusions}

The results of the evaluation of the sensitivity (susceptibility, permittivity) of the diploid cell line derived from the kidney of $P$. nathusii, demonstrated a high level of its permittivity to causative agents of Vesicular stomatitis, Epizootic hemorrhagic disease and Peste des petits ruminants.

Reproduction of the above-mentioned viral agents in the cell culture was accompanied by expressed cytopathic effect beginning from the very first passage without preliminary adaptation of the viruses to cells.

P. nathusii inhabits and migrates throughout the area from southern and middle Europe to the middle east. Considering the sensitivity of the cell culture derived from the kidney of this species to BTV, RVFV, LSDV and MV, demonstrated earlier [10], and to VSV, EHDV and PPRV, described in this paper, we can conclude that the diploid cell line derived from $P$. nathusii kidney has a broad spectrum of susceptibility to viruses from different taxonomic groups. It allows us to recommend using them for primary virus isolation and other virological studies, as well as to consider this species as a possible source, carrier (transmitter) and reservoir for the transmissible viral diseases mentioned above.

\section{Material And Methods}

\section{Cell cultures}


In this study, the diploid cell line P. nathusii (Pipistrellus nathusii Keyserling \& Blasius, 1839; Chiroptera: Microchiroptera: Vespertilionidae) kidney cell strain (PKDCL) developed earlier [10] and cryopreserved in liquid nitrogen at different passage levels was used.

To assess the reproduction and dynamics of the development of the cytopathogenic effect (CPE), we used the following susceptible cell cultures as controls for each virus:

- CV-1 line (African Green Monkey Kidney Fibroblast continuous cell line);

- L-929 (clone strain L cell culture from subcutaneous tissue of mouse),

- GT (primary goat kid testicle cell subculture)

obtained from The Cell Cultures Collection of the Federal Research Center for Virology and Microbiology [11].

\section{Viruses}

Another object of this study are several transmissible viruses belonging to different families,

- Vesicular stomatitis virus (VSV, Rhabdoviridae), Indiana strain with infectivity $6,75 \pm 0,25 \mathrm{lg}$ $\mathrm{TCID}_{50} / \mathrm{cm}^{3}$ in cell culture L-929;

- Epizootic hemorrhagic disease virus (EHDV), Alberto strain, infectivity $6,25 \pm 0,25 \mathrm{lg} \mathrm{TCID}_{50} / \mathrm{cm}^{3}$, in CV-1cell culture;

- The 8935 Akabane virus strain (AKAV) at the activity $6,75 \pm 0,25 \mathrm{lg} \mathrm{TCID}{ }_{50} / \mathrm{cm}^{3}$ in cell culture CV-1

- Peste des petits ruminants virus (PPRV), «45G 37/35-К» strain, with activity 4,25 $\pm 0,25 \mathrm{lg}$ ТЦД сM3 in cell culture from testicles of goatling (GT).

The viruses received from The State Collection of Microorganisms Causing Dangerous or Highly Dangerous Diseases, Including Zooanthroponoses, and Exotic Diseaseshttp://ckp-rf.ru/ckp/441429/

\section{Medium and solutions}

To promote cell growth, we used Eagle's Medium and Dulbecco's Modified Eagle Medium (DMEM, HyClone, USA), fetal bovine serum (FBS, HyClone, USA) and antibiotics (ciprofloxacin $10 \mu \mathrm{g} / \mathrm{ml}$ and amphotericin $5 \mu \mathrm{g} / \mathrm{ml}$ ).

When changing the medium, we dispersed the cell monolayer using a mixture of $0.25 \%$ trypsin solution and $0.02 \%$ Versene solution $1: 3$ pre-warmed to $37^{\circ} \mathrm{C}$.

The cell cultures were maintained by a conventional method of serial passages at $37 \pm 0,5^{\circ} \mathrm{C}$ in an atmosphere containing elevated gaseous carbon dioxide levels, up to $5 \%$, and a relative humidity of $95 \%$.

Methods 
The sensitivity (permissivity) of the $P$. nathusii kidney diploid cell line (PKDCL) was tested by inoculation with a corresponding viral material, with a multiplicity of infection (MOI) of $0.1-0.01 \mathrm{TCD}_{50} / \mathrm{cell}(50 \%$ tissue culture infectious dose), into a culture flask containing a confluent cell monolayer. Exposition lasted 60 min. After that, we added a supporting medium containing $2 \%$ FBS and incubated the infected culture at $37,0 \pm 0,5^{\circ} \mathrm{C}$ until the $\mathrm{CPE}$ of the virus became visible.

The infectious activity of a virus was determined by titration in a virus-sensitive (susceptible) cell culture, using the time of onset of CPE as an index. The virus titer was determined using the Reed and Muench method.

DNA extraction was performed with QIAamp_DNA Mini kit/ QIAamp® Viral RNA kit (QIAGEN, Germany) according to the instruction manual. $[13,14]$.

The authenticity of PPRV and VSV was confirmed using molecular genetic methods. For the detection of the PPRV genome, we used ID Gene ${ }^{\mathrm{TM}}$ Peste des Petits Ruminants Duplex kit (IDvet, France) and primers as described by Kwiatek et al. [12]. To detect the VSV genome, we used primers proposed by Rodriguez et. al [13] followed by sequencing the obtained PCR product.

Purification of PCR products was performed with a Cleanup Standard kit (Evrogen, Russia) followed by Sanger sequencing with BigDye Terminator Cycle Sequencing Kit v3.1 (Applied Biosystems, Austin, TX, U.S.A.) on Applied Biosystem Genetic Analyser 3130 XL (USA).

For additional confirmation of the PPRV authenticity, we performed a neutralization test according to a convenient scheme [15-18] and ELISA test (ID Screen® PPR Competition test kit, France). For this purpose, we tested serum samples taken from three PPRV immunized sheep ("zero-serum") and specific sera collected from animals on the 14th day post-inoculation of the viral material obtained from a titration of a virus in the P. nathusii kidney diploid cell line from wells of 7th dilution after the development of a pronounced CPE.

The animal experimental protocols were approved by the Ethics Committee of the Federal Research Center for virology and Microbiology (Protocol № 1 from February 1, 2021) and were conducted according to Russian legislation and international (ARRIVE) guidelines in animal biosecurity facilities (77.99.03.001.K.000702.0405) of the Federal Research Center for Virology and Microbiology (FRCVM), Volginskiy, Russia.

Virus-neutralizing activity of a specific serum was determined using PPRV (strain 45G35/37-K, MOI of $5,75 \mathrm{lg} \mathrm{TCD}_{50} / \mathrm{CM}^{3}$ ) grown in a green monkey kidney continuous cell line (Vero).

\section{Declarations}

\section{Acknowledgments}


The authors wish to thank Andrey Lunitsin for literature searching and advising and Andrey Gogin for editing the text.

\section{Author contributions}

Povolyaeva 0. - investigation, visualization, writing - original draft

Chadaeva A. - investigation

Sindryakova I. - investigation

Lapteva O. - investigation

Yurkov S. - conceptualization, methodology, project administration, supervision

\section{Competing Interests Statement}

The authors declare that they have no known competing financial interests or personal relationships that could have appeared to influence the work reported in this paper.

\section{References}

1. Calisher, C. H. et al. Bats: Important Reservoir Hosts of Emerging Viruses // Clin. Microbiol. Rev. 2006. Vol. 19, № 3. P. 531-545.

2. Wang, L. F., Walker, P. J. \& Poon, L. L. M. Mass extinctions, biodiversity and mitochondrial function: are bats 'special' as reservoirs for emerging viruses? /. Curr. Opin. Virol. Elsevier B.V, Vol. 1, (2011).

3. Drexler, J. F. et al. Amplification of Emerging Viruses in a Bat Colony // Emerg. Infect. Dis. 2011. Vol. 17, № 3. P. 449-456.

4. Moratelli, R. \& Calisher, C. H. Bats and zoonotic viruses: can we confidently link bats with emerging deadly viruses? /. Mem. Inst. Oswaldo Cruz, Vol. 110, (2015).

5. Zhang, H. et al. A Novel Bat Herpesvirus Encodes Homologues of Major Histocompatibility Complex Classes I and II, C-Type Lectin, and a Unique Family of Immune-Related Genes // J. Virol. 2012. Vol. 86, № 15. P. 8014-8030.

6. Eckerle, I. et al. Bat Airway Epithelial Cells: A Novel Tool for the Study of Zoonotic Viruses // PLoS One / edMunster V.J. 2014. Vol. 9, № 1. P. e84679.

7. Crameri, G. et al. Establishment, Immortalisation and Characterisation of Pteropid Bat Cell Lines // / ed. 2009. Vol. 4, № 12. P. e8266.

8. Mourya, D. T. et al. Establishment of cell line from embryonic tissue of Pipistrellus ceylonicus bat species from India \& its susceptibility to different viruses. //. Indian J. Med. Res, Vol. 138, 224-231 (2013). 
9. Povolyaeva, O. et al. Listeria monocytogenes infection of bat pipistrellus nathusii epithelial cells depends on the invasion factors inla and inlb // Pathogens. 2020. Vol. 9, № 11. P. 1-21.

10. Povolyaeva, O. S. et al. Biological characteristics and permissiveness to viruses of diploid kidney cells strain from the bat Nathusius' pipistrelle (Pipistrellus nathusii Keyserling \& Blasius, 1839; Chiroptera: Microchiroptera: Vespertilionidae) // Probl. Virol, Vol. 66, (2021).

11. Yurkov, S. G. et al. Z.N.B.F.A.V. Catalog of the collection of cell cultures.Pokrov, 2010.89p.

12. Kwiatek, O. et al. Quantitative one-step real-time RT-PCR for the fast detection of the four genotypes of PPRV // J. Virol. Methods. 2010. Vol. 165, № 2. P. 168-177.

13. Rodriguez, L. L. et al. Rapid detection of vesicular stomatitis virus New Jersey serotype in clinical samples by using polymerase chain reaction // J. Clin. Microbiol. 1993. Vol. 31, № 8. P. 2016-2020.

14. Rodriguez, L. L. et al. Rapid detection of vesicular stomatitis virus New Jersey serotype in clinical samples by using polymerase chain reaction // J. Clin. Microbiol. 1993. Vol. 31, № 8. P. 2016-2020.

\section{Figures}

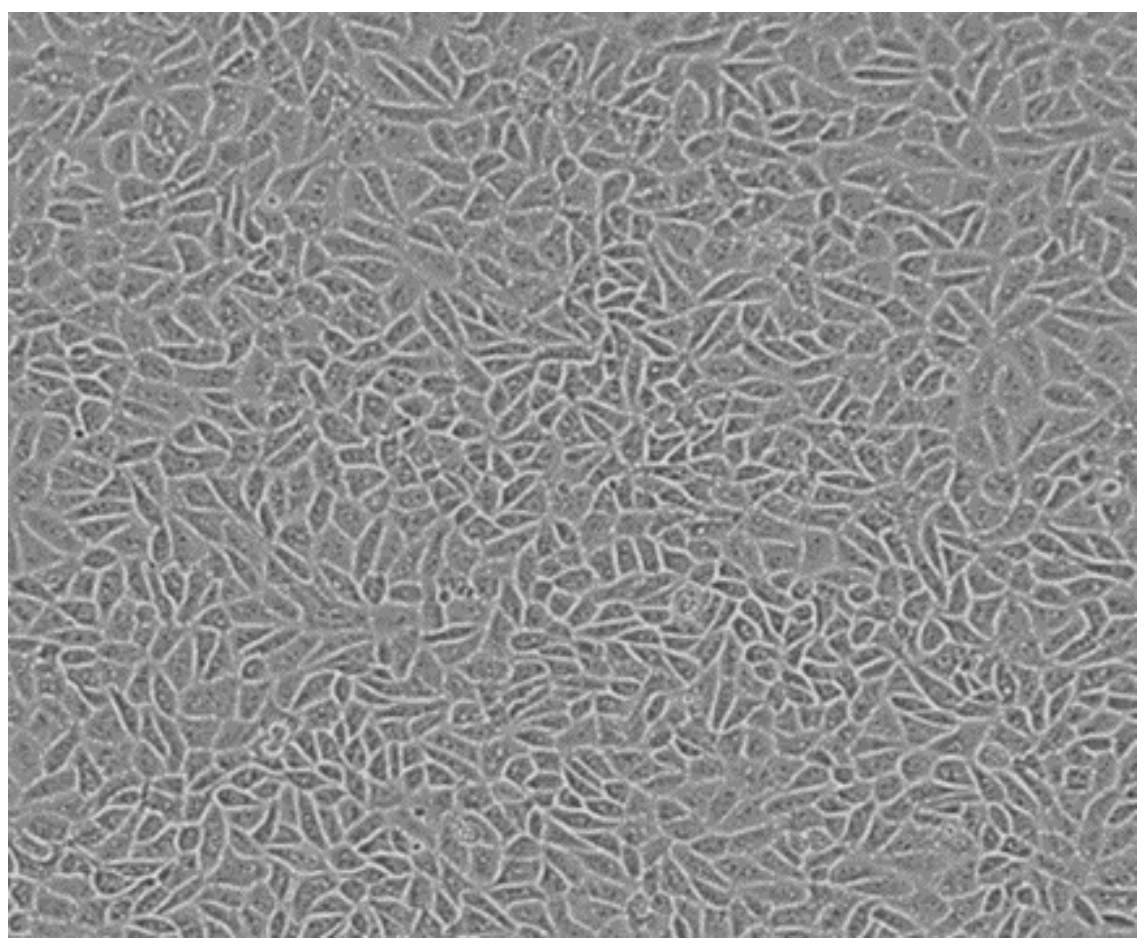

\section{Figure 1}

Confluent monolayer of PKDCL at the twelfth passage level (magnification $\times 150$ ) 

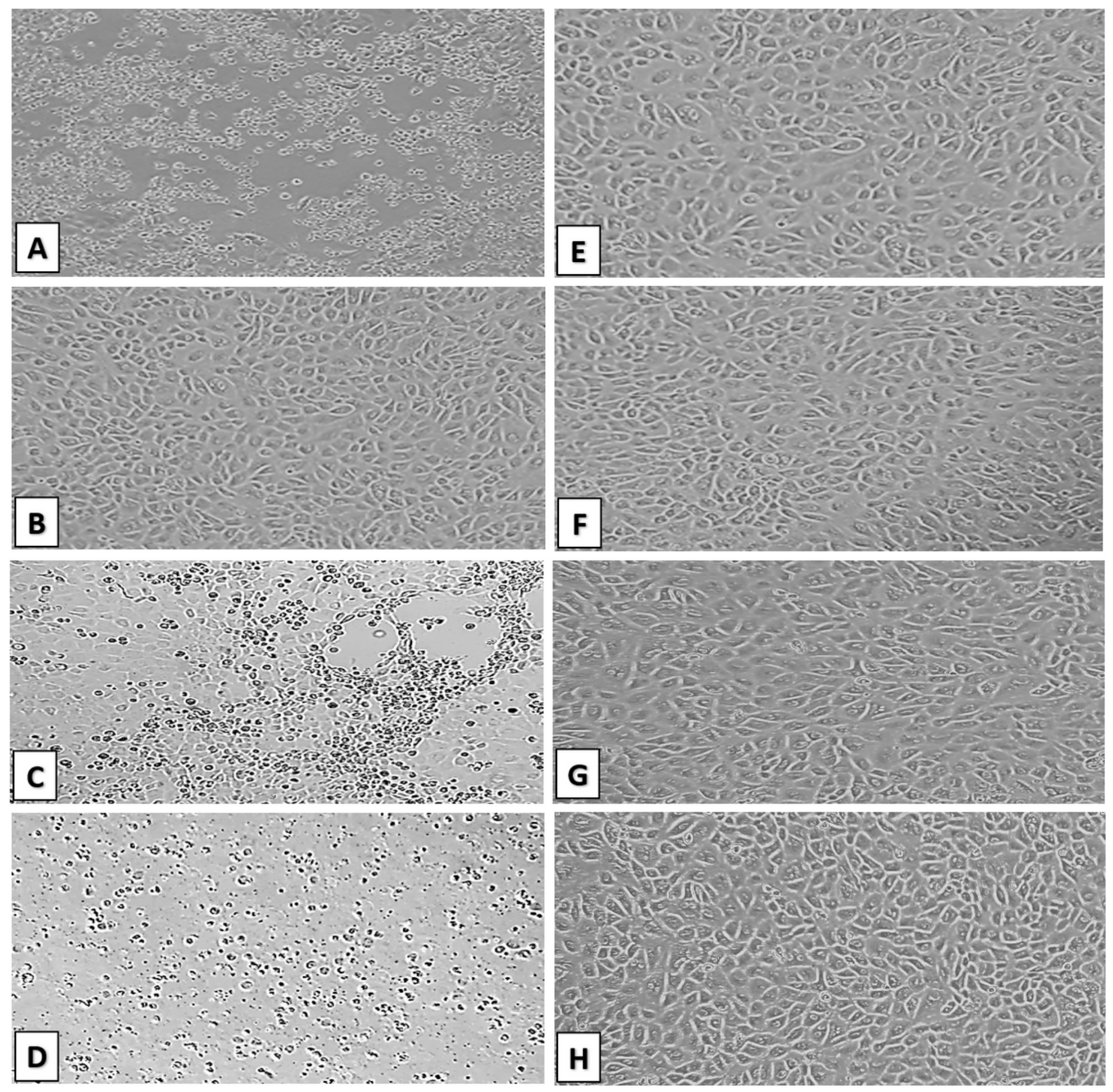

Figure 2

CPE caused by the viruses in DCLPK at different passages (A-D: experimental and E-H: control): A - CPE caused by VSV, 12th passage; B- CPE caused by AKAV, 16th passage; $C$ - CPE caused by EHDV, 25th passage; D - CPE caused by PPRV, 42nd passage; E-H - control (uninfected) cell cultures, 12th, 16th, 25th and 42nd passage, respectively (magnification $\times 150$ ). 